Revista Destaques Acadêmicos, Lajeado, v. 10, n. 4, 2018. ISSN 2176-3070

DOI: http://dx.doi.org/10.22410/issn.2176-3070.v10i4a2018.2009

http://www.univates.br/revistas

\title{
ANÁLISE COMPARATIVA DE ISOLAMENTO TÉRMICO ENTRE PAINÉIS PRÉ-MOLDADOS, ALVENARIA DE VEDAÇÃO DE BLOCOS DE CONCRETO E BLOCOS CERÂMICOS, PARA ATENDER A NBR 15575, PARA FINS DE CONFORTO TÉRMICO
}

\author{
Ana Cristina Fiegenbaum ${ }^{1}$, Marcelo Freitas Ferreira ${ }^{2}$
}

\begin{abstract}
Resumo: Os usuários buscam cada vez mais conforto e qualidade de vida, e a temperatura no ambiente é fator essencial para atingir esses patamares. Com base nisso, foi elaborado este trabalho com o objetivo de analisar o desempenho térmico de três paredes com materiais diferentes: painéis pré-moldados de concreto, blocos de concreto e blocos cerâmicos, que foram analisados com a aplicação de revestimentos de argamassa e pintura. Foram realizadas medições de temperatura interna e externa com um termo-higrômetro, seguindo a NBR 15575 (ABNT, 2013). Foram feitos também os cálculos através da NBR 15220-2 (ABNT, 2005) de resistência e transmitância térmica do material. O protótipo de blocos cerâmicos apresentou a menor temperatura, principalmente após o reboco e com pintura na cor branca, onde se pôde analisar que antes dessa etapa a temperatura interna chegava a atingir até $6^{\circ} \mathrm{C}$ superiores à externa, diferença que caiu para $1,5^{\circ} \mathrm{C}$. Comprovou-se que a cerâmica é a mais eficiente para vedação, sendo o único material que se aproximou dos valores estabelecidos pela norma, com uma transmitância térmica de $2,526 \mathrm{~W} /\left(\mathrm{m}^{2} . \mathrm{K}\right)$, enquanto que os Protótipos 1 e 2 atingiram 4,403 e 2,718 (W/ $\left(\mathrm{m}^{2} . \mathrm{K}\right)$, respectivamente.
\end{abstract}

Palavras-chave: Conforto. Desempenho. Painéis pré-moldados. Blocos de concreto. Blocos cerâmicos.

\section{INTRODUÇÃO}

No período clássico, as habitações eram vistas como um espaço habitável que deveria ter funcionalidade. Hoje em dia, no entanto, ela precisa ser vista também como um elemento com eficiência energética, que proporciona

1 Graduanda em Engenharia Civil, Universidade do Vale do Taquari anacristinafiegenbaum@hotmail.com

2 Mestre em Engenharia e Tecnologia de Materiais, na Pontifícia Universidade Católica do Rio Grande do Sul, marcelo.ferreira@univates.br 
conforto térmico, acústico e com baixo consumo de energia (LAMBERTS et al. 2014). Conforme Frota e Schiffer (2007), as principais variáveis associadas ao conforto térmico são a temperatura, umidade, velocidade do ar e radiação solar, tendo relações com as chuvas, a permeabilidade do solo e a topografia.

Este trabalho tem como objetivo realizar o estudo sobre o comportamento térmico de diferentes tipos de paredes, que neste caso será a alvenaria de vedação com o uso de painéis de concreto pré-moldados, blocos de concreto e blocos cerâmicos, que deverá atender as especificações da NBR 15575 (ABNT, 2013) e da NBR 15220 (ABNT, 2005).

\section{REFERENCIAL TEÓRICO}

\subsection{Conceitos de conforto térmico}

Conforme a NBR 15220 (ABNT, 2005) a condutividade térmica é uma "Propriedade física de um material no qual se verifica um fluxo de calor constante, com densidade de $1 \mathrm{~W} / \mathrm{m}^{2}$, quando submetido a um gradiente de temperatura uniforme de 1 Kelvin por metro". De acordo com a NBR 152201 (ABNT, 2005), a resistência total de um elemento é a soma das resistências térmicas das camadas de um elemento, resultado da divisão da espessura pelo coeficiente de condutividade térmica. Segundo Costa (2003), a transmitância térmica é a soma dos coeficientes de transmissão de calor externo e do coeficiente de condutibilidade térmica dos materiais, sendo determinada como o inverso da resistência térmica total.

\subsection{Tipos de paredes e revestimentos}

As vedações verticais externas e internas servem para limitar os cômodos e ambientes de uma edificação no sentido vertical, e junto com as esquadrias criar condições habitáveis, protegendo do frio, do calor, da chuva e de outros agentes indesejáveis. A alvenaria de vedação com blocos, conforme Moraes (2011), caracteriza-se pelo uso de blocos de melhor qualidade, de projeto de produção, treinamento da mão-de-obra, uso de compensadores, evitando a quebra, redução do desperdício e melhoria na organização. A introdução de pré-moldados no canteiro de obras aumenta a industrialização e diminui a variabilidade dos sistemas, diminuindo a ocorrência de patologias (FRANCO, 2013).

Segundo Santos (2008), os revestimentos de argamassa devem proteger as edificações de agentes agressivos, regular a superfície e servir de base para outros revestimentos. Deve ter textura constante e ser livre de imperfeições. Conforme Ikematsu (2007), a tinta é um material utilizado em diversas situações devido as suas propriedades estéticas e protetoras. Geralmente as tintas utilizadas para melhoria do conforto térmico são de cor branca. 


\section{METODOLOGIA}

Este trabalho visa um estudo comparativo de desempenho térmico entre diferentes tipos de paredes com a utilização de três protótipos, levando em conta requisitos da NBR 15575 (ABNT, 2013), analisando a resistência e transmitância térmica, antes e após a aplicação de revestimentos (argamassa e pintura). Os protótipos foram construídos na Linha Geraldo, no interior do município de Estrela - RS, em uma área livre de objetos e com ótima incidência solar. Todos foram feitos com os mesmos tamanhos, espaçados entre si com dimensões externas de $1 \mathrm{~m} \times 1 \mathrm{~m} \times 1 \mathrm{~m}$ e foi construída uma laje de $8 \mathrm{~cm}$ e um telhado com mesmo material com caimento de $10 \%$, todos com a face que possui a abertura virada para o Norte. As estruturas não tem ventilação, possuem apenas uma abertura vedada com isopor com dimensões de $20 \mathrm{~cm}$ x $20 \mathrm{~cm}$, permitindo a entrada do sensor do aparelho de medição de temperatura. Na Figura 1 podese visualizar a planta de situação do local.

Figura 1 - Planta de Situação do local de construção dos protótipos

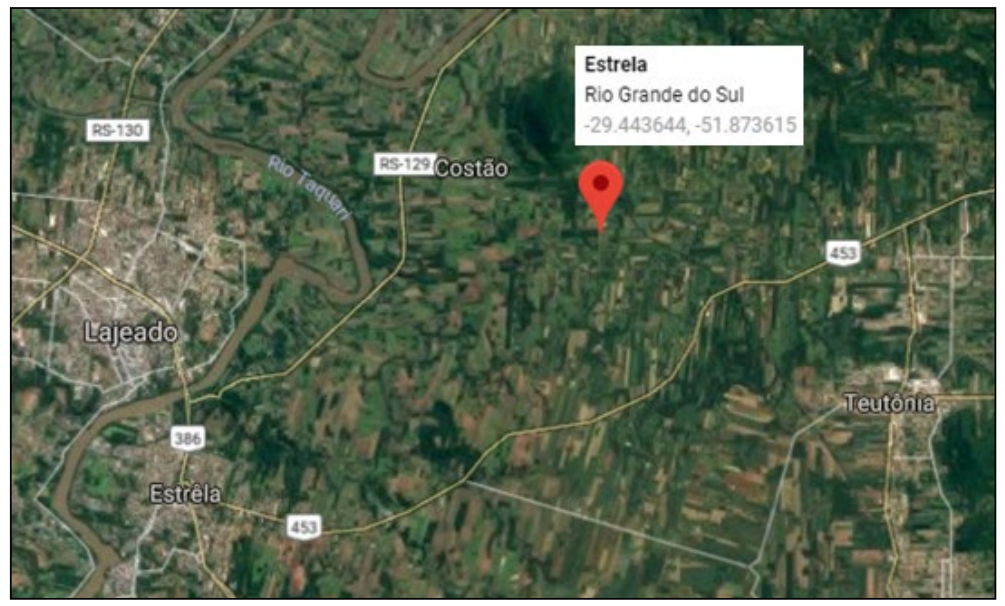

Fonte: Autor (2018).

\subsection{Métodos avaliativos de desempenho térmico}

Para verificação do desempenho térmico, baseando-se nas normas de desempenho térmico de edificações, foram seguidos os métodos da NBR 15575 (ABNT, 2013), coletando-se temperaturas internas e externas para comparações de desempenho. $\mathrm{O}$ cálculo da Transmitância e Resistência Térmica foi desenvolvido de acordo com a NBR 15220 (ABNT, 2005) para verificar o cumprimento dos requisitos mínimos do material de vedação, considerando os protótipos após a aplicação do revestimento de argamassa interna e externa. 
Os dados foram coletados por um termo-higrômetro que coleta a temperatura interna e externa, (máxima e mínima) e a umidade relativa do ar interna em formato digital. Possui um cabo com uma ponta de inox de 2,8 metros para maior precisão. O dia analisado corresponde a um dia de verão, precedido por um dia com características semelhantes. As medições foram realizadas durante 5 dias nas etapas antes e após a aplicação do reboco, e durante 3 dias nas demais etapas, todos com as mesmas condições climáticas apresentando sol e sem ocorrência de chuva no dia anterior, sendo que foram coletadas 4 medições por dia, às 09:00, 12:30, 16:00 e às 19:30 horas. As etapas de medições estão dispostas abaixo na Tabela 1.

Tabela 1 - etapas de medições e coletas de dados

\begin{tabular}{c|c}
\hline Etapa & Etapas de medições \\
\hline 1 & Após a aplicação do revestimento interno e antes do revestimento externo; \\
\hline 2 & Após a aplicação do revestimento externo; \\
\hline 3 & Após a aplicação do Selador e da tinta Branca; \\
\hline 4 & Após a aplicação da tinta Marrom; \\
\hline
\end{tabular}

Fonte: Autor (2017).

\subsection{Etapas de construção e montagem dos protótipos}

Para a construção utilizaram-se blocos cerâmicos e de concreto vazados, ambos com espessura de $14 \mathrm{~cm}$, além dos painéis pré-moldados com $10 \mathrm{~cm}$ de espessura. Com os protótipos concluídos, conforme Figura 2, se iniciou a fase de análise de medições.

Figura 2 - Conclusão dos 3 protótipos

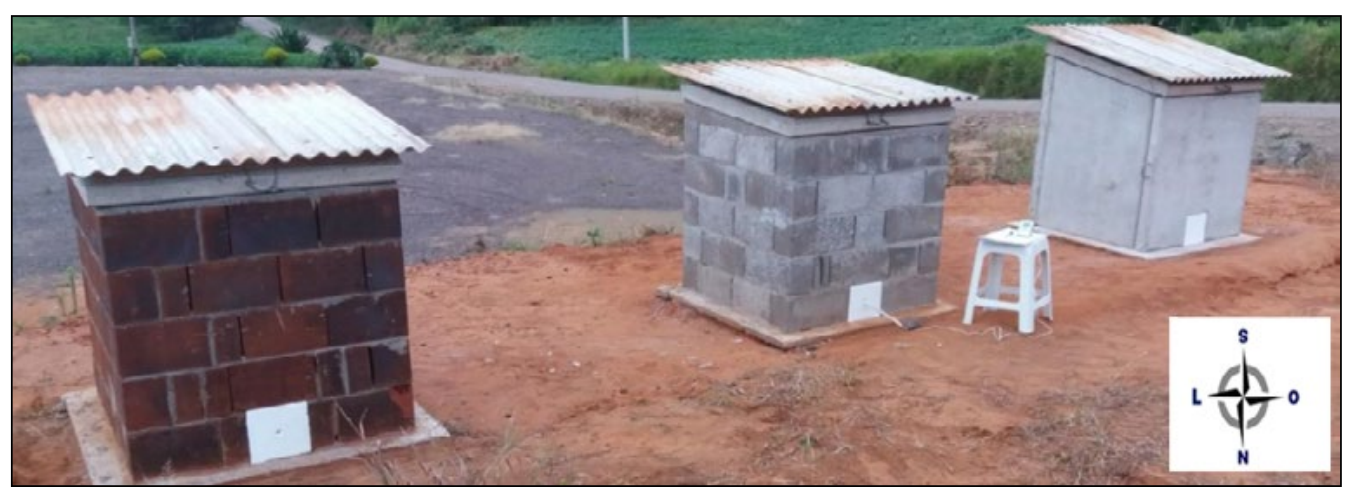

Fonte: Autor (2018). 


\section{ANÁlisES DE DADOS E RESULTADOS}

A fim de alcançar os objetivos e fazer a comparação do desempenho térmico dos materiais que foram usados na construção e revestimento dos protótipos, aplicou-se os cálculos conforme o método da NBR 15220-2/2005, desenvolvendo assim gráficos a partir das medições realizadas.

\subsection{Resultados dos cálculos através da NBR 15220-2/2005}

Na Tabela 1 seguem os resultados dos cálculos através da NBR 152202/2005, considerando-se a espessura dos blocos e painéis, com camada interna e externa de $2 \mathrm{~cm}$ de reboco nos Protótipos com blocos (Protótipos 2 - Blocos de Concreto e Protótipo 3 - Blocos Cerâmicos). O Protótipo 1 é composto por paredes de Painéis Pré-Moldados.

Tabela 1 - Resultados das análises térmicas dos protótipos

\begin{tabular}{l|r|r|r}
\hline CÁLCULOS & Protótipo 1 & Protótipo 2 & Protótipo 3 \\
\hline Resistência Térmica Total $\left(\left(\mathrm{m}^{2} \cdot \mathrm{K}\right) / \mathrm{W}\right)$ & 0,227 & 0,368 & 0,396 \\
\hline Transmitância Térmica Total $\left(\mathrm{W} /\left(\mathrm{m}^{2} \cdot \mathrm{K}\right)\right.$ & 4,403 & 2,718 & 2,526 \\
\hline
\end{tabular}

Fonte: Autor (2018).

Conforme a NBR 15220 (ABNT, 2005), a Resistência Térmica da parede é determinada através da soma das resistências das diversas camadas da parede, e corresponde à dificuldade da transmissão de calor. Quanto maior a resistência térmica, menor será o calor que irá atravessar a parede. A norma NBR 15575$5 / 2013$ estabelece requisitos de transmitância e capacidade térmica para as zonas bioclimáticas em geral. Seguem na Tabela 2 as especificações para a Zona 2.

Tabela 2 - Requisitos da Zona Bioclimática 2

\begin{tabular}{l|l}
\hline \multicolumn{2}{c}{ Zona Bioclimática 2} \\
\hline Transmit. Térmica $\mathrm{U}\left(\mathrm{W} / \mathrm{m}^{2} . \mathrm{K}\right)$ & $\mathrm{U} \leq 2,5$ \\
\hline Capac. Térmica CT $\left(\mathrm{kJ} / \mathrm{m}^{2} . \mathrm{K}\right)$ & $\mathrm{CT} \geq 130$ \\
\hline
\end{tabular}

Fonte: Adaptado de NBR 15575-5/2013.

Comparando os dados das Tabelas 1 e 2, em relação à Transmitância Térmica, pode-se perceber que apenas o Protótipo 3 se aproxima do valor estipulado pela Norma, que é até $2,5 \mathrm{~W} /\left(\mathrm{m}^{2} . \mathrm{K}\right)$, enquanto que o protótipo 1 fica muito distante desse valor. Conforme a norma NBR 15220-2/2005, o país é dividido em 8 zonas bioclimáticas e cada uma deve atender as suas 
recomendações de conforto térmico. Para cada zona são estabelecidas tipos de paredes e coberturas. Ela indica um valor de transmitância térmica ideal como $\mathrm{U} \leq 3,0$.

\subsection{Resultados das medições de Temperatura}

Seguem abaixo as análises feitas em cada uma das 4 etapas.

\subsubsection{Etapa 1}

$\mathrm{Na}$ primeira etapa foram analisadas as medições de temperatura realizadas durante 5 dias, antes da aplicação do revestimento externo, o reboco. Para não ocorrerem discrepâncias nos resultados, em cada horário medido descartou-se o dia com temperatura mais alta e o dia com a temperatura mais baixa, e fez-se a média da temperatura dos demais dias, que obtiveram temperaturas parecidas. A média de temperaturas está exposta na Tabela 3.

Tabela 3 - Média das medições de temperatura da Etapa 1

\begin{tabular}{c|c|c|c|c}
\hline \multicolumn{5}{c}{ ETAPA 1 } \\
\hline Temp & P1 & P2 & P3 & Ext \\
\hline $09: 00$ & 21,267 & 22,100 & 22,333 & 21,367 \\
\hline $12: 30$ & 28,467 & 28,067 & 27,500 & 28,800 \\
\hline $16: 00$ & 31,233 & 30,567 & 29,733 & 30,967 \\
\hline $19: 30$ & 31,000 & 30,733 & 30,367 & 27,533 \\
\hline
\end{tabular}

Fonte: Autor (2018).

Com estes dados foi gerado o Gráfico 1, que mostra a temperatura externa e a temperatura interna dos 3 protótipos em cada um dos 4 horários medidos. 
Gráfico 1 - Temperaturas medidas na Etapa 1

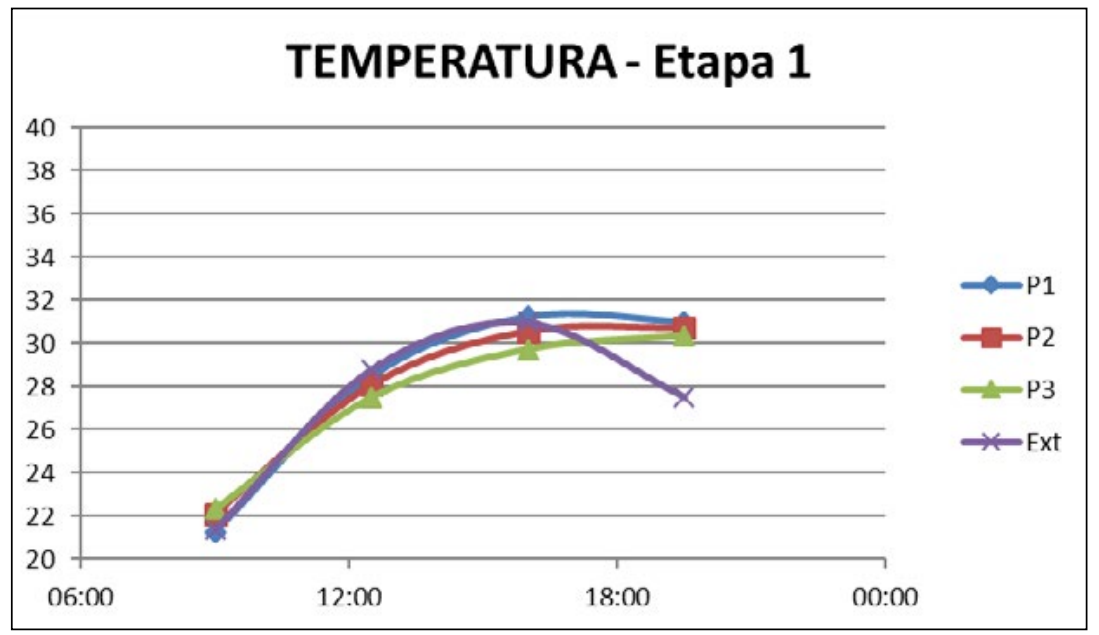

Fonte: Autor (2018).

Observa-se uma pequena diferença entre os 3 protótipos, com temperatura crescente do Protótipo 3 para o Protótipo 1, concluindo-se que o Protótipo de blocos cerâmicos é o que apresenta menor temperatura ao longo do dia. Pela manhã, na primeira medição, o mesmo protótipo apresenta uma temperatura maior que os demais. Com isso, podemos ver que o material cerâmico leva mais tempo para esquentar como para resfriar, o que se deve ao fato de possuir uma condutividade térmica menor que o concreto.

Outra observação que pode ser feita é de que pela manhã, às 09:00 horas, a temperatura externa é próxima à da interna nos protótipos, sendo que nos Protótipos 2 e 3 ela é um pouco mais alta em relação à externa, o que é comum em construções quando se tem uma temperatura mais baixa. Já no horário do meio dia, às 12:30 horas, podemos observar uma diferença significativa entre as temperaturas internas com a externa, sendo esta bem maior em relação aos protótipos.

Às 16:30 horas a temperatura externa fica intermediária com a dos protótipos, maior que a do Protótipo 1, mas menor que os demais. No final do dia, ocorre a maior diferença entre a temperatura externa e a interna, enquanto que a temperatura externa teve queda considerável, a temperatura interna está estabilizando, começando a baixar de forma devagar no Protótipo 1, e nos outros dois ela ainda está aumentando em relação à medição da tarde.

Isso mostra exatamente o comportamento das temperaturas ao longo do dia, que tende a aumentar consideravelmente ao longo do dia e baixar rapidamente ao anoitecer, diferentemente do que acontece dentro de uma construção ou residência, onde o papel das paredes é impedir que o calor passe para o ambiente interno. A temperatura nos protótipos demora mais para 
subir, mas permanece aumentando por mais tempo no final do dia, atingindo picos menores que externamente, com exceção do Protótipo 1, que por ser composto apenas por uma chapa de concreto, sem ventilação, é mais quente que os demais.

Podemos observar no gráfico que o pico de temperatura interna e externa não ocorrem no mesmo horário, enquanto que a maior temperatura externa é registrada entre às 15 e 16 horas, a maior temperatura interna é atingida somente entre às 17 e 18 horas.

\subsubsection{Etapa 2}

Na segunda etapa foram avaliadas as medições de temperatura feitas durante 5 dias, depois da aplicação do revestimento externo, ou seja, os $2 \mathrm{~cm}$ da camada de reboco. Da mesma maneira que na primeira etapa, em cada horário medido descartou-se o dia com temperatura mais alta e mais baixa, fazendo-se uma média dos demais dias, cujas temperaturas eram parecidas. Essa média de temperaturas está na Tabela 4.

Tabela 4 - Média das medições de temperatura da Etapa 2

\begin{tabular}{c|c|c|c|c}
\hline \multicolumn{5}{c}{ ETAPA 2 } \\
\hline Temp & P1 & P2 & P3 & Ext \\
\hline $09: 00$ & 21,833 & 22,300 & 23,000 & 20,500 \\
\hline $12: 30$ & 28,100 & 26,067 & 25,967 & 29,333 \\
\hline $16: 00$ & 32,867 & 30,233 & 30,000 & 33,100 \\
\hline $19: 30$ & 34,167 & 32,300 & 31,867 & 26,700 \\
\hline
\end{tabular}

Fonte: Autor (2018).

Com estes dados gerou-se o Gráfico 2, que apresenta a temperatura externa e a temperatura interna dos 3 protótipos em cada um dos 4 horários medidos. 
Gráfico 2 - Temperaturas medidas na Etapa 2

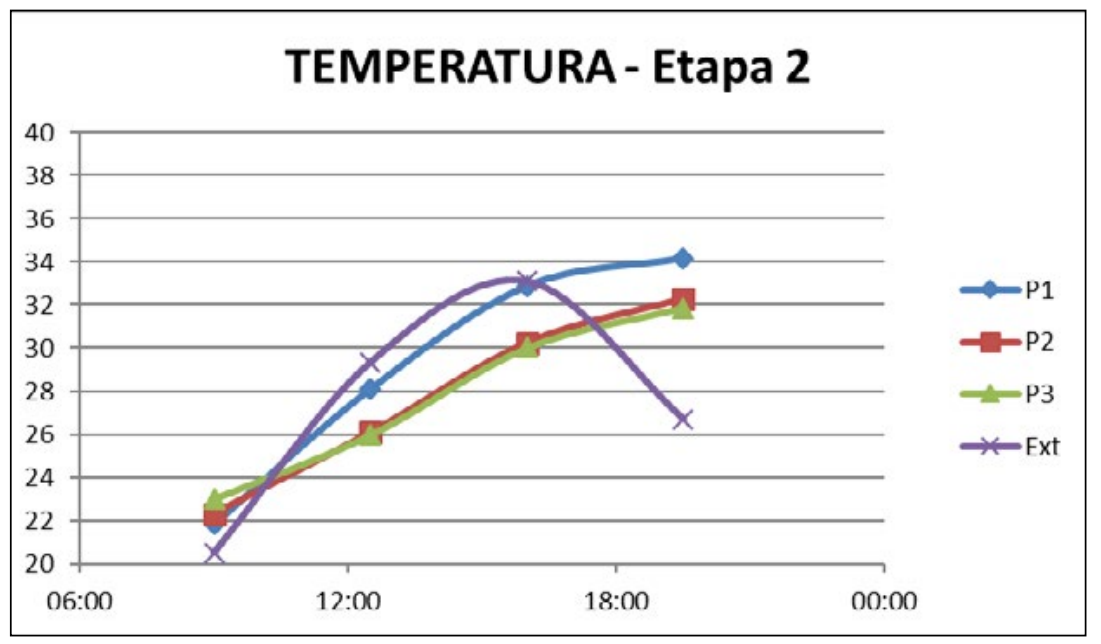

Fonte: Autor (2018).

Com a visualização do gráfico, podem-se observar vários aspectos e comparar com a primeira etapa. Como foi aplicado o reboco apenas nos Protótipos 2 e 3, pois o painel não necessita desse acabamento, pode-se constatar que a temperatura continua crescente do Protótipo 3 para o 1, mas dessa vez com uma diferença maior de temperatura do primeiro em relação aos outros, pois está se comparando dois protótipos com $18 \mathrm{~cm}$ de espessura (14 cm do bloco mais duas camadas de $2 \mathrm{~cm}$ de reboco + camada de ar) com um protótipo com apenas $10 \mathrm{~cm}$ de camada única de concreto. Em relação às demais comparações, o gráfico segue o mesmo comportamento em relação à primeira etapa, com aumento rápido de temperatura externa e posteriormente queda da mesma forma, assim como o comportamento interno, que demora mais para esquentar, assim como para resfriar.

\subsubsection{Etapa 3}

$\mathrm{Na}$ terceira etapa foram avaliadas as medições de temperatura feitas por apenas 3 dias, depois da aplicação da pintura de cor branca, visto que o objetivo era somente fazer uma comparação sobre a eficiência do uso de cores diferentes. Segue na Tabela 5 a média dos 3 dias de medições. 
Tabela 5 - Média das medições de temperatura da Etapa 3

\begin{tabular}{c|c|c|c|c}
\hline \multicolumn{5}{c}{ ETAPA 3 } \\
\hline Temp & P1 & P2 & P3 & Ext \\
\hline $09: 00$ & 20,700 & 21,267 & 21,667 & 20,700 \\
\hline $12: 30$ & 23,700 & 22,933 & 22,800 & 27,467 \\
\hline $16: 00$ & 27,033 & 26,300 & 25,933 & 28,167 \\
\hline $19: 30$ & 27,033 & 26,700 & 26,267 & 25,467 \\
\hline
\end{tabular}

Fonte: Autor (2018).

Com estes dados elaborou-se o Gráfico 3, que mostra a temperatura externa e a temperatura interna dos 3 protótipos em cada um dos 4 horários medidos. Observa-se uma diferença maior entre as temperaturas internas com a externa, comparado aos Gráficos 1 e 2 . A temperatura interna não ultrapassa a externa nos períodos intermediários, nos horários das 12:30 horas e das 16:00 horas, apenas pela manhã e no período vespertino, com menor intensidade do que nas etapas anteriores. Além de se ter uma redução significativa de temperatura durante o dia, ao anoitecer essa diferença é maior ainda. Nas etapas anteriores tinha-se diferença de 3 a $4^{\circ} \mathrm{C}$ da interna para a externa, chegando até $6^{\circ} \mathrm{C}$, após a pintura de cor branca essa diferença caiu para até $1,5^{\circ} \mathrm{C}$, em que a interna ainda é maior que a externa.

Gráfico 3 - Temperaturas medidas na Etapa 3

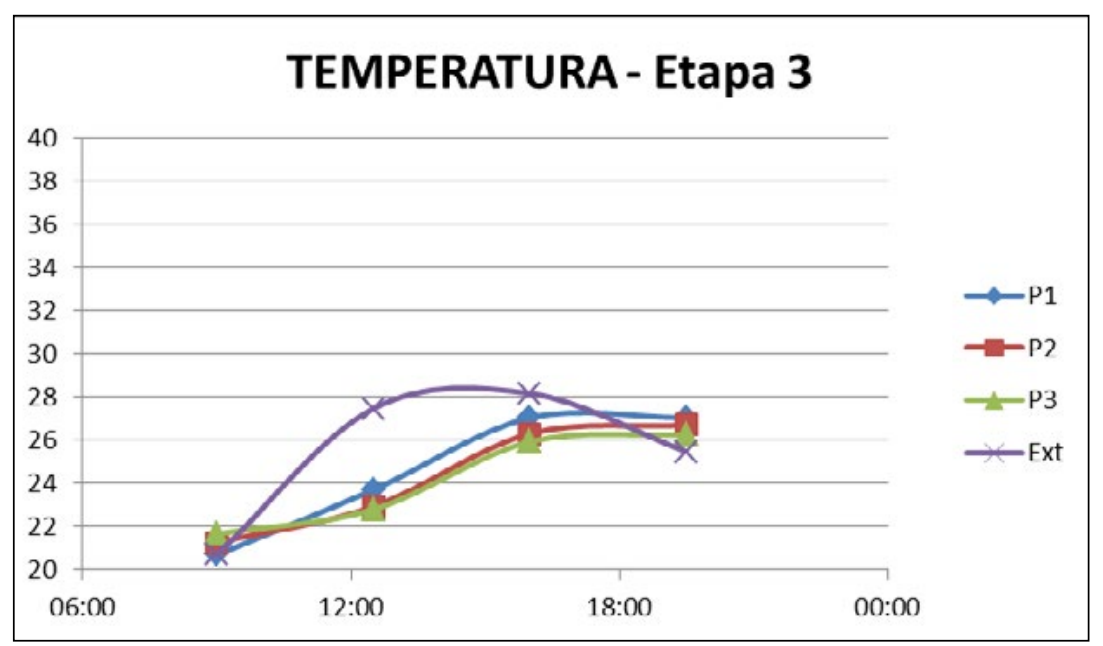

Fonte: Autor (2018). 


\subsubsection{Etapa 4}

$\mathrm{Na}$ quarta etapa foram verificadas as medições de temperatura feitas por 3 dias, depois da pintura de cor marrom. Segue na Tabela 6 a média dos 3 dias de medições.

Tabela 6 - Média das medições de temperatura da Etapa 4

\begin{tabular}{c|c|c|c|c}
\hline \multicolumn{5}{c}{ ETAPA 4 } \\
\hline Temp & P1 & P2 & P3 & Ext \\
\hline $09: 00$ & 22,800 & 23,033 & 23,367 & 21,033 \\
\hline $12: 30$ & 30,500 & 27,833 & 27,200 & 30,467 \\
\hline $16: 00$ & 36,200 & 33,367 & 32,033 & 32,533 \\
\hline $19: 30$ & 36,767 & 33,467 & 33,167 & 29,567 \\
\hline
\end{tabular}

Fonte: Autor (2018).

Com estes valores foi criado o Gráfico 4, que mostra a temperatura externa e a temperatura interna dos 3 protótipos em cada um dos 4 horários medidos. Com a análise do gráfico, podem-se observar vários aspectos em relação à etapa anterior. Após a pintura das paredes com a tinta marrom, a temperatura interna voltou novamente a apresentar valores e diferenças maiores em relação à externa. Como nas outras etapas, a temperatura externa aumenta mais rapidamente, porém agora tem-se um registro de temperatura interna maior que a externa já na segunda medição, às 12:30 horas, e diferenças enormes no final da tarde, em que a temperatura interna chega a superar a externa em aproximadamente $7^{\circ} \mathrm{C}$ no Protótipo 1, que foi o mais atingido pela cor escura e teve seu comportamento muito alterado. 
Gráfico 4 - Temperaturas medidas na Etapa 4

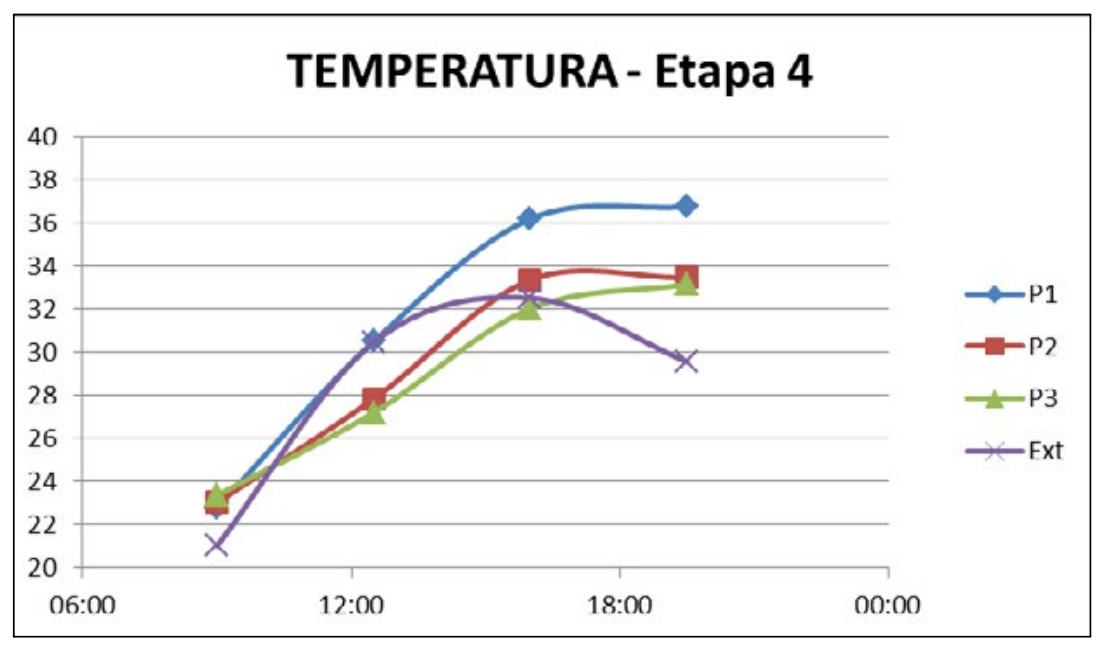

Fonte: Autor (2018).

Comparando-se um protótipo com o outro, observa-se o mesmo comportamento dos outros gráficos, onde o melhor resultado encontrado sempre é o do Protótipo 3, de blocos cerâmicos. Os painéis pré-moldados vêm sendo muito usados e o mercado vem estimulando o seu uso devido aos diversos ganhos e vantagens que eles trazem, por isso deve-se ter o cuidado de escolher um material que atinja também os fatores mínimos de desempenho térmico, visto que isso não é levado em conta nem informado pelo fornecedor na hora da aquisição dos produtos, e como visto nos gráficos, um simples painel proporciona um conforto inferior comparado com um bloco com camada de ar e rebocado.

\section{CONCLUSÃO}

Os materiais usados neste trabalho, como os painéis pré-moldados, os blocos de concreto e blocos cerâmicos, são frequentes nas construções do nosso dia a dia, e por isso optou-se por analisá-los e fazer uma comparação térmica entre eles, além de analisar a melhora após a aplicação de diversos revestimentos, visto que existem normas técnicas que trazem certas exigências, como a NBR 15220 (ABNT, 2005) e a NBR 15575 (ABNT, 2013).

Com os cálculos das resistências e transmitâncias térmicas, pôde-se observar a diferença dos materiais, sendo que o protótipo de blocos cerâmicos foi o que melhor atendeu as normas, com temperaturas e umidades mais baixas, enquanto que o protótipo de blocos de concreto permaneceu na faixa intermediária, e o protótipo de painéis pré-moldados com temperaturas e umidades mais altas, o que deve ser levado em consideração, visto que muitas obras são realizadas sem se preocupar com esse fator. 
A utilização de processos construtivos industrializados, como os prémoldados, que reduzem a mão de obra e o tempo de execução, tem ganhado cada vez mais destaque no mercado brasileiro, não só pelo custo, como também pela maior qualidade dos elementos e do acabamento, porém muitos não levam em conta o fator de desempenho térmico, acústico e estanque desses materiais e não exigem isso dos fabricantes. Para cada obra e tipo de construção deve ser analisado o que precisa ser atendido, buscando espessuras e acréscimo de materiais especiais que melhorem essas características.

Além de a temperatura ser mais baixa no protótipo de blocos cerâmicos, pela manhã sempre teve temperaturas maiores, mostrando que possui um maior atraso térmico, levando assim mais tempo para permitir a passagem de calor. A umidade também se apresentou menor, comprovando que a cerâmica absorve menos água do que o concreto, observando assim que é uma boa solução para melhorar o conforto das residências.

A tinta térmica, por sua vez, melhorou a condição da etapa anterior, porém não teve o resultado esperado, provavelmente por se tratar de uma tinta de cor muito escura, e que deveria ser melhor analisada. É uma sugestão para um próximo trabalho, de analisar mais essa tinta, dividindo em várias etapas, pintando as paredes externas, internas e o telhado, além de deixar aberturas para que se tenha ventilação natural.

A procura por conforto térmico é cada vez maior, visto que a preocupação ambiental e o gasto com energia elétrica são fatores importantes não apenas no momento de executar, mas também na manutenção das construções. Devese pensar na melhor maneira de isolar o ambiente e dos melhores materiais e revestimentos a serem usados na obra, levando em conta vários fatores, como o custo, durabilidade, estética, conforto térmico e acústico.

\section{REFERÊNCIAS}

ASSOCIAÇÃO BRASILEIRA DE NORMAS TÉCNICAS. NBR 15220 - Desempenho Térmico de Edificações - Rio de Janeiro, 2005.

. NBR 15575 - Desempenho Térmico de Edificações - Rio de Janeiro, 2005.

COSTA, Ennio C. Física aplicada à construção: conforto térmico. $4^{\circ}$ ed. São Paulo, 2003.

DE MORAES, Eduardo et al. Alvenaria de vedação com blocos de concreto. 2011. Cartilha da Comunidade da Construção de Recife/PE. Disponível em: <http:/ /www. comunidadeda construcao. com.br/upload/ativos/245/anexo/anexo04cart.pdf>. Acesso em: 10 de agosto de 2017.

FRANCO, Luiz. O uso de pré-moldados em alvenaria estrutural. 2013. IBRACON, 72 a ed. Disponível em: <http://ibracon.org.br/Site_revista/Concreto_Construcoes/ revistainterna_69.php $>$. Acesso em: 08 de agosto de 2017. 
FROTA, Anésia B.; SCHIFFER, Sueli R. Manual do conforto térmico. $8^{\text {a }}$ ed. São Paulo, 2007.

IKEMATSU, Paula. Estudo da refletância e sua influência no comportamento térmico de tintas refletivas e convencionais de cores correspondentes. 2007. Dissertação de mestrado (Construção civil e urbana) da Escola Politécnica da Universidade de São Paulo. Disponível em: <http:/ / www.pcc.usp.br/files/text/ thesis/2007_12_Paula_Ikematsu_KAI.pdf>. Acesso em: 01 de setembro de 2017.

LAMBERTS, Roberto et al. Eficiência energética na arquitetura. 2014. [3.ed.] Rio de Janeiro.

SANTOS, Heraldo. Ensaio de aderência das argamassas de revestimento. 2008. Curso de Especialização em Construção Civil da Escola de Engenharia da UFMG. Belo Horizonte. Disponível em: < http:/ / pos.demc.ufmg.br/novocecc/trabalhos/pg1/ Monografia\%20Heraldo \%20 Barbosa.pdf>. Acesso em: 08 de setembro de 2017. 